\title{
Rare Case of Female Pelvic Masses: Multiple Angioleiomyomas of Broad Ligament
}

\author{
Avinash Mane ${ }^{1}$, S.S.Kumbhar ${ }^{2 *}$, Sujata.R.Kanetkar ${ }^{3}$, Shoaib Khoja ${ }^{4}$, Divya Brahmbhatt ${ }^{5}$ \\ ${ }^{1}$ Assistant Professor, ${ }^{2}$ Associate Professor, ${ }^{3}$ Professor and Head, ${ }^{4,5}$ Tutor, Department of Pathology, Krishna Institute of Medical Sciences Deemed to be \\ University, Karad, India
}

DOI: $10.36347 /$ simcr.2020.v08i06.004

| Received: 01.06.2020 | Accepted: 09.06.2020 | Published: 13.06.2020

*Corresponding author: S.S.Kumbhar

Abstract

Case Report

Angioleiomyoma is a benign mesenchymal neoplasm composed of smooth muscle cell and thick walled blood vessels. Angioleiomyomas are most commonly seen in the skin of extremities and it is uncommon in uterus. Broad ligament angioleiomyomas is more uncommon than uterine. Patient with uterine angioleiomyomas usually present with excessive bleeding per vaginum compared to uterine leiomyomas. Abdominal pain is also observed in many cases of angioleiomyomas of pelvic cavity which is believed to be related to ischemia due to vascular contracture. Histologically, angioleiomyomas are divided into 3 subtypes namely - Capillary, Cavernous and Mixed. Here we present a rare case of Capillary Angioleiomyoma of broad ligament in a case of $42 \mathrm{yr}$ old female presented with pelvic mass.

Keywords: Angioleiomyoma, smooth muscle, broad ligament.

Copyright @ 2020: This is an open-access article distributed under the terms of the Creative Commons Attribution license which permits unrestricted use, distribution, and reproduction in any medium for non-commercial use (NonCommercial, or CC-BY-NC) provided the original author and source are credited.

\section{INTRODUCTION}

Angioleiomyoma (AL) is a rare type of leiomyoma arising from smooth muscle cell and containing thick walled vessels. It is a benign soft tissue tumor. Most often found in the subcutis of lower extremities. Few cases of uterine Angioleiomyoma have been reported in the literature. Broad ligament AL's are extremely rare [1]. ALs is commonly observed in $4^{\text {th }}$ and $5^{\text {th }}$ decade of life. Uterine AL's mostly present with excessive per vaginal bleeding compared to routine leiomyomas of uterus. On other hand, AL arising from broad ligament presents with persistent lower abdominal pain and mass effects. We are presenting this case of 42 year old female presented with multiple AL's of broad ligaments. Not only for its rarity, but also to put emphasis on histopathological diagnosis.

\section{Case Report}

A 42 year old female presented with chief complaints of low grade pain and mass per abdomen of 6 months duration to gynecology department. Based on these symptoms, ultrasonography, colposcopic examination was advised. USG revealed multiple adnexal masses, probably originating from broad ligament. Hematological and biochemical investigations including CA125 were within normal limits. Patient underwent panhysterectomy along with excision of masses.

Grossly, multiple, soft, grey brown, spongy masses having predominantly grey brown, soft cut surface with focal cystic areas noted. Fig. 1 and Fig.2

On Microscopy revealed vascular tumor with classical perivascular concentric arrangement of elongated cells having spindle shaped nuclei with regular chromatin, smooth nuclear borders, rounded nuclear ends noted. Cytoplasm was eosinophilic, fibrillary in nature. Fig.3 \& Fig.4

Based on microscopic findings diagnosis of multiple Angioleiomyomas arising from broad ligament was given.

\section{Gross DeSCRIPTION}

Multiple, soft, grey brown, spongy masses having predominantly grey brown, soft cut surface with focal cystic areas noted. Fig.1 \& Fig.2 


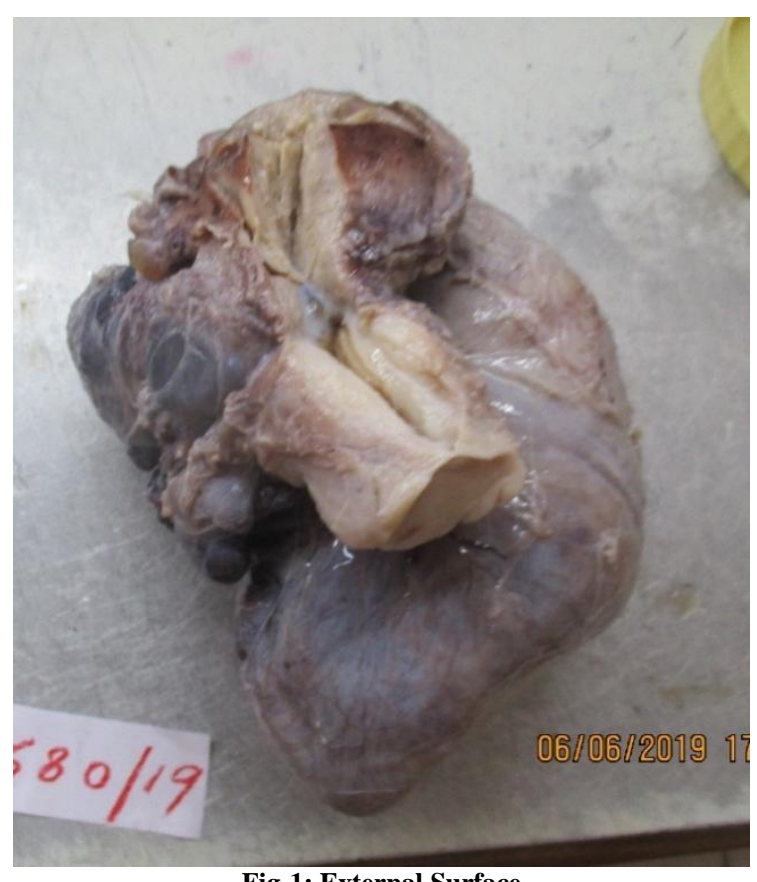

Fig-1: External Surface

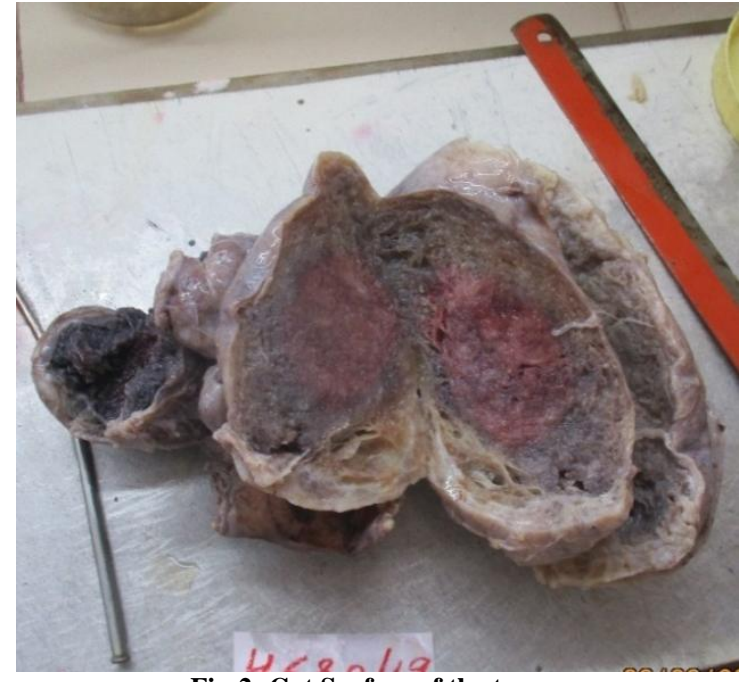

Fig-2: Cut Surface of the tumor

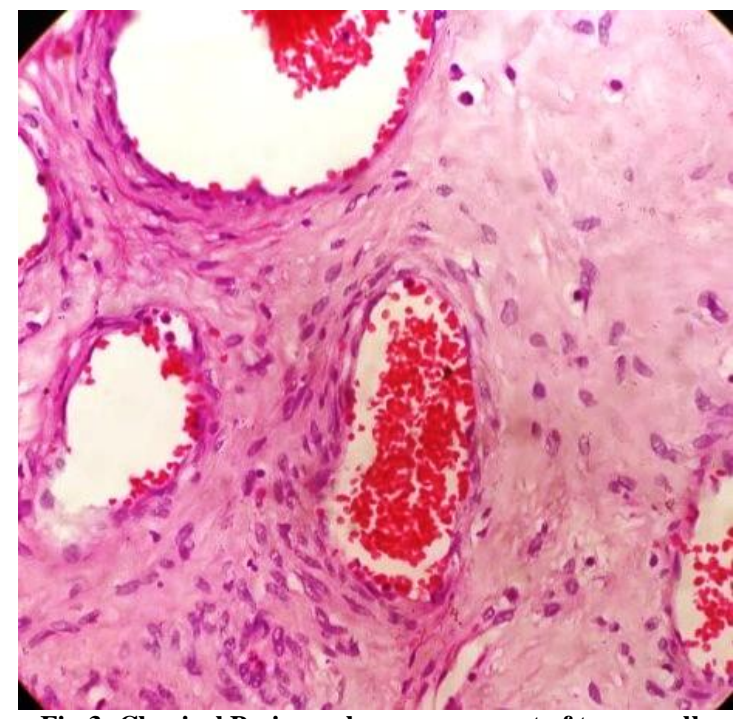

Fig-3: Classical Perivascular arrangement of tumor cells

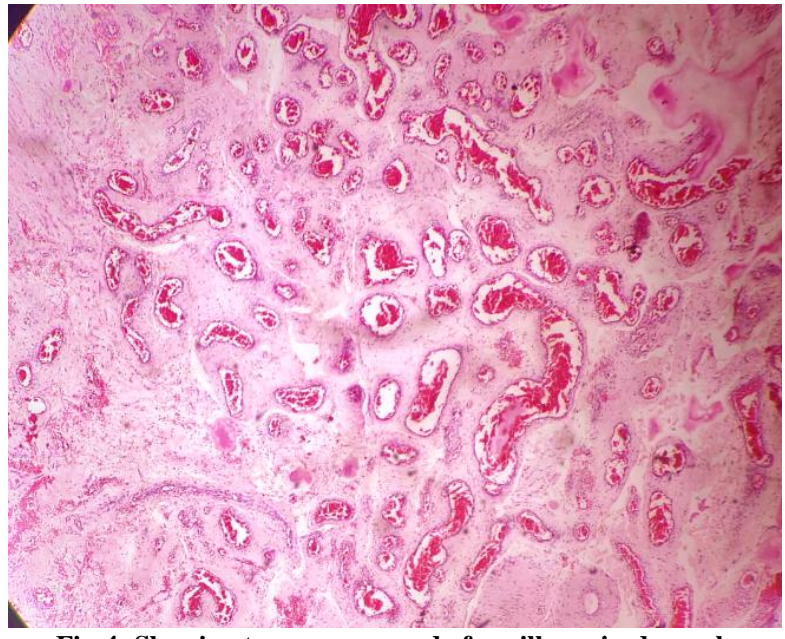

Fig-4: Showing tumor composed of capillary sized vessels

\section{DISSCUSSION}

Angioleiomyoma (AL) is benign mesenchymal neoplasm composed of smooth muscle cells and thick walled blood vessels. AL is most commonly seen in the skin of extremities and it is uncommon in uterus. Broad ligament $\mathrm{AL}$ is more uncommon than uterine counterpart [2]. Patient with uterine AL's usually presents with excessive bleeding per vaginum, compared to uterine leiomyomas. Abdominal pain is also observed in many cases of AL's of pelvic cavity which is belived to be related to ischemia due to vascular contracture [3, 4]. Our patient presented with mass per abdomen and persisting lower abdominal pain for last 6 months. Grossly, multiple masses [5] are seen adhered to uterine perimetrium. External surface was smooth, grey white, glistening. Cut section revealed very classical soft, spongy, grey brown, cystic areas. Microscopy classically revealed thick walled vasculature rimmed by bundle of smooth muscle.

Histologically, AL are divided into 3 subtypes namely- Capillary, Cavernous and mixed [4]. Our case belong to capillary type of AL. Ultrasonography is the initial investigation of choice but most of the times USG fails to correctly diagnose AL's of broad ligament, same is true in our case also. USG revealed multiple, soft tissue masses adhered to uterus and probable diagnosis of? Soft tissue tumor,? Ovarian neoplasm was given, for further evaluation MRI was suggested. MRI impression was given as multiple neoplasm of ovarian origin so, hysterectomy was performed. On gross examination, both the ovaries were separetly identified and masses were seen originating from broad ligament. Differential diagnosis includes Angiofibroma, angiomyolipomas, angiofibroblastoma, and perivascular epitheloid tumors. In our case, capillaries were thick walled and perivascular cell exhibit classical blunt ends, there was no lipomatous component, no epitheloid morphology was observed. So, final diagnosis for Angioleiomyoma (AL) arising from broad ligament was given. 
Duhing and Ayer [5] in their study observed that there was no recurrence following excision in any of their cases. Complication likes spontaneous rupture of tumor, consumption coagulopathy and pseudomigs syndrome have been reported [6-8]. Our patient had an uneventful post operative course and recovery.

\section{Conclusion}

Thus to conclude we are presenting this case for its rarity, unusual clinical presentation and prompt histopathological diagnosis.

\section{REFRENCES}

1. Weiss SW, Goldblum JR, editors. Benign tumor of smooth muscle. In: Enzinger and Weiss's Soft Tissue. 5th ed. St. Louis: Mobsy; 2001: 699700.

2. Agarwal S, Gupta SK, Tejwani N. Angioleiomyoma of broad ligament. J Gynecol Endosc Surg. 2009; 1:116-7.
3. Wang CP, Chang YL, Sheen TS. Vascular leiomyoma of the head and neck. Laryngoscope. 2004; 114:661-5.

4. Bommanahalli BP, Murthy N. Angioleiomyoma: A rare variant of uterine leiomyoma. NJIRM. 2014; $5: 131-2$.

5. Duhig JT, Ayer JP. Vascular leiomyoma. A study of sixtyone cases. Arch Pathol. 1959; 68:424-30.

6. Culhaci N, Ozkara E, Yüksel H, Ozsunar Y, Unal E. Spontaneously ruptured uterine angioleiomyoma. Pathol Oncol Res. 2006; 12:50-1.

7. Handler M, Rezai F, Fless KG, Litinski M, Yodice PC. Uterine angioleiomyoma complicated by consumptive coagulopathy. Gynecol Oncol Case Rep. 2012; 2:89-91.

8. Thomas S, Radhakrishnan L, Abraham L, Matthai A. Uterine angioleiomyoma with atypia, raised CA-125 levels, and pseudo-meigs syndrome: An alarming presentation. Case Rep Pathol. 2012; 2012:519473. 